\title{
Profile of Patients with Gaster Perforation at Dr. Moewardi General Hospital Surakarta in The Period of January-December 2018
}

\author{
Imam Hafidh Zaini1*, Ida Bagus Budhi2
}

1Departement of Surgery, Faculty of Medicine, Sebelas Maret University, Surakarta, Indonesia

${ }^{2}$ Departement of Surgery, Digestive Division, Faculty of Medicine, Sebelas Maret University, Surakarta, Indonesia

\author{
A R T I C L E I N F O \\ Keywords: \\ Gastric Perforation \\ Retrospective \\ Dr. Moewardi
}

\section{*Corresponding author: \\ Imam Hafidh Zaini \\ E-mail address: \\ hafidhbedah@gmail.com}

All authors have reviewed and approved the final version of the manuscript.

\section{https://doi.org/10.32539/bsm.v5i6.325}

\begin{abstract}
A B S T R A C T
Background: A gastric perforation is a form of hollow digestive organ perforation in which the entire thickness of the stomach wall is injured. Perforation of hollow organs can be suspected based upon the clinical picture, and the diagnosis becomes obvious through an image of free air on imaging performed. Methods: Data of patient characteristics were observed retrospectively from medical records of patients diagnosed with gastric perforation between January and December 2018. Results: Between January and December 2018, 45 patients with gastric perforation were identified, with data distributed by gender. There were 36 women $(80 \%)$ and 9 men $(20 \%)$ in the group. Based on the age group, 32 patients $(71 \%)$ were distinguished by the age group over 40 years and 13 patients $(29 \%)$ under 40 years of age. When viewed from the location of the gastric perforations, it was found that 4 patients $(9 \%)$ had a perforation in the antrum, 36 patients $(80 \%)$ in the Prepylorus, and 5 patients $(11.2 \%)$ in the major curvature. Data on analgesic use revealed 32 patients $(71 \%)$ had a history of taking analgesics and 13 patients $(29 \%)$ without a history of taking analgesics. Conclusion: In 2018, the majority of gastric perforation patients at Dr. Moewardi Hospital were female (80\%), with the highest age group being over 40 years $(71 \%)$ and the most gastric perforations occurring in the pylori $(80 \%)$. The number of patients with gastric perforation who had previously used herbs and analgesics was higher $(70 \%)$ than those who had not. Thus, the results of this retrospective study are consistent with previous research findings and can be used to continue research into the relationships (correlations) between the aforementioned variables.
\end{abstract}

\section{Introduction}

A gastric perforation is a form of hollow digestive organ perforation in which the entire thickness of the stomach wall is injured. Perforation of hollow organs may be suspected based upon patients' clinical picture and the diagnosis becomes obvious through an image of free air on imaging performed. Since the peritoneum covers the entire stomach, perforation in the gastric wall causes communication between the gastric lumen and the peritoneal cavity. If the perforation is acute, there is no time for the inflammatory reaction to occur and the gastric content will fill the peritoneal cavity causing chemical peritonitis. ${ }^{1}$

In adults, the most common cause of gastric perforation is peptic ulcers. Peptic ulcer perforation is a surgical emergency. Perforation is a serious complication of peptic ulcer and patients with acute abdominal pain may have an increased risk of mortality and morbidity. The prevalence of perforation in peptic ulcer patients is about 5\%. More than half of the cases occur in women than men. The peak age of incidence is 40-60 years. Gastric perforation causes mortality of $1.3-20 \%$. The 30-day mortality rate was $20 \%$ and the 90-day mortality rate was 30\%. ${ }^{2}$ However, since the discovery of proton pump inhibitors (PPIs), perforations due to peptic ulcers have begun to decrease in incidence. At least, $30 \%$ of gastric perforations are malignant. Meanwhile, in children, the most common 
cause of gastric perforation is trauma. The data show

that the incidence of perforation increases due to both blunt and sharp trauma. ${ }^{1}$

\section{Methods}

This was a descriptive retrospective study based on medical record data regarding gastric perforation obtained from the General Hospital Dr. Moewardi in Surakarta from January to December 2018. During the data collection, 45 patients with gastric perforation were identified.

\section{Statistical analysis}

The data were collected retrospectively by analyzing the patient's medical records. The criteria used in this study were gender, age group at risk, location of the gastric perforation, and drinking habits and analgesics. The information gathered was organized into groups based on the criteria and then presented as percentages.

\section{Result}

According to the results of this retrospective study, there were 45 cases of gastric perforation at Dr. Moewardi General Hospital Surakarta from January 1, 2018, to December 31, 2018. From 45 research subjects, 9 (20\%) were male and 36 (80\%) were female [Table 1]. Of the 45 study subjects, 32 patients (71\%) were in the age group above 40 and 13 patients (29\%) were under 40 [Table 2]. It was also found that 4 patients $(9 \%)$ had a gastric perforation in antrum 4 (9\%), 36 patients (80\%) in Prepylorus, and 5 patients $(11, \%)$ in curvature major [Table 3]. Regarding the use of the analgesic, 32 patients (71\%) had a history of taking analgesics, and 13 patients (29\%) without a history of taking analgesics [Table 4].

Table 1. Incidence of Gastric Perforation Based on Gender

\begin{tabular}{lcc}
\hline Gender & F & \% \\
\hline Male & 9 & 20 \\
Female & 36 & 80 \\
Total & $\mathbf{4 5}$ & $\mathbf{1 0 0}$ \\
\hline
\end{tabular}

Table 2. Incidence of Gastric Perforation Based on Age

\begin{tabular}{lcc}
\hline Age & F & \% \\
\hline$<40$ year & 32 & 71 \\
$>40$ year & 13 & 29 \\
Total & $\mathbf{4 5}$ & $\mathbf{1 0 0}$ \\
\hline
\end{tabular}

Table 3. Incidence of Gastric Perforation Based on Location

\begin{tabular}{lcc}
\hline Location & F & \% \\
\hline Antrum & 4 & 9 \\
Pylorus & 36 & 80 \\
Major Curvature & 5 & 11 \\
Total & $\mathbf{4 5}$ & $\mathbf{1 0 0}$ \\
\hline
\end{tabular}


Table 4. Incidence of Gastric Perforation Based on History of Taking Analgesics

\begin{tabular}{lcc}
\hline History of Taking Analgesics & F & \% \\
\hline Taking Analgesics & 32 & 71 \\
Not taking Analgesics & 13 & 29 \\
\hline Total & $\mathbf{4 5}$ & $\mathbf{1 0 0}$ \\
\hline
\end{tabular}

\section{Conclusion}

The incidence of recurrent vulvovaginal candidiasis is high in female and related to various factors such as genetic, host, habit, idiopathic and the candida itself. Recurrent vulvovaginal candidiasis can cause variety effects such as decreased quality of life, depression, and sexual dysfunction. Diagnosis recurrent vulvovaginal candidiasis is based on anamnesis, physical examination, microscopic examination and fungal culture. The purpose of recurrent vulvovaginal candidiasis treatment is to eliminate the predisposition factors of the host and to give the right regiment based on culture and microbial resistance test.

\section{References}

1. Chung KT, Shelat VG (2017). Perforated peptic ulcer update. World J Gastrointestinal Surg, 9 (1): 1-12.

2. Gonenc M, Dural AC, Celik F, et al (2014). Enhanced postoperative recovery pathways in emergency surgery: a randomized controlled clinical trial. Am J Surg. 2007 (6): 807-14.

3. Kamel BG, Cassaro S (2019). Gastric Perforation. Stat Pearls Publishing

LCC. https:/ /www.ncbi.nlm.nih.gov/books / NBK519554/ - Accessed July 2019.

4. Rizqah., Nur'aini., And noviyanto, F. (2016). Evaluation of the Use of Peptic Ulcer Desease at the Bhayangkara Brimob Hospital, 2015. Tanggerang: Tanggerang Muhammadiyah High School; Vol III: No.2

5. Kapoor VK et al. 2017. Stomach anatomy. Pubmed. Soreide K, Thorsen K, Harrison EM, Bingener J, Moller MH, yeboah MO, soreide JA (2016). Perforated Peptic Ulcer. Lancet, 386 (10000): 1288-1298.

6. Koto K, Asrul, and Muradi. Characteristic of gastric perforation type and histopathology at Haji Adam
Malik general hospital Medan-Indonesia. Bali Med J. 2016. 5 (1): 166-168.

7. Plaskett J, Chinnery G, Thomson D, Thomson S, Dedekind B, Jonas E.Rapunzel syndrome: A South African variety. S. Afr. Med. J. 2018 Jun 26; 108 (7): $559-562$

8. Prabu, V. and Shivani, A, 2014.An Overview of History Pathogenesis and Treatment of perforated peptic ulcer Disease with Evaluation of prognostic Scoring in Adults, Annals of Medical and Health Science Research, Vol 4. India. 2014.

9. Rizqah., Nur'aini., And noviyanto, F. (2016). Evaluation of the Use of Peptic Ulcer Desease at the Bhayangkara Brimob Hospital, 2015. Tanggerang: Tanggerang Muhammadiyah High School; Vol III: No. 2

10. Saviero SD et al (2014). Diagnosis and treatment of perforated or bleeding peptic ulcers: 2013 WSES position paper. World Journal of Emergency Surgery, 9 (45): 1-15. 